\title{
Toward Improving Coastal-Fog Prediction (C-FOG)
}

\author{
Clive E. Dorman ${ }^{1,2}$ (D) Andrey A. Grachev ${ }^{3,4,5} \cdot$ Ismail Gultepe ${ }^{5,6,7}$. \\ Harindra J. S. Fernando 5
}

Received: 14 August 2021 / Accepted: 24 August 2021 / Published online: 3 November 2021 (c) The Author(s), under exclusive licence to Springer Nature B.V. 2021

Investigation into marine fog was greatly expanded by three events in the 20th Century. The first was the sinking of Titanic in the early morning hours of 15 April 1912 in the North Atlantic Ocean, during which, according to a historic account, “.....at $11.30 \mathrm{pm} \mathrm{a}$ slight but definite haze appeared dead ahead of the ship... and a faint haze obscuring the iceberg lasted for $10 \mathrm{~min}$ until collision at $11.40 \mathrm{pm}$ " (Lawrence 2000). G.I. Taylor was sent to the accident area in 1913 as the meteorologist in an investigative team, where he recorded many fogs and thermal inversions, and took photographs of flat-top smoke from his own ice-scout ship Scotia, allowing investigations of fog from a (thermo-) dynamical perspective. The second was an international agreement in the 1930s on a synoptic weather observation code that set standards and established the systematic collection and archiving of ships' weather observations. The third was an explosion of worldwide shipping around 1950. By the early 2000s, enough ship observations had been collected to construct a detailed climatology of marine fog (Dorman et al. 2017). It was found that the two greatest non-polar marine-fog occurrences are in the north-west regions of the Pacific and Atlantic Oceans that include Atlantic Canada.

During the 1913 Scotia expedition, Taylor obtained ground-breaking ship-based surface and kite observations over the Grand Banks in Atlantic Canada (Taylor 1915). From these and later measurements, Taylor hypothesized that the advection of warm and moist

Clive E. Dorman

cdorman@ucsd.edu

1 Integrative Oceanography Division, Scripps Institution of Oceanography, University of California, San Diego, La Jolla, CA 92093-0209, USA

2 Department of Geological Sciences, San Diego State University, San Diego, CA 92182-1020, USA

3 NOAA Physical Sciences Laboratory/Cooperative Institute for Research in Environmental Sciences, University of Colorado, Boulder, CO 80305-3328, USA

4 Boundary Layer Research Team/Atmospheric Dynamics and Analytics Branch, DEVCOM Army Research Laboratory, White Sands, NM 88002, USA

5 Department of Civil and Environmental Engineering and Earth Sciences, Department of Aerospace and Mechanical Engineering, University of Notre Dame, Notre Dame, IN 46556, USA

6 Meteorological Research Division (MRD), Environment and Climate Change of Canada (ECCC), Toronto, ON M3H-5T4, Canada

7 Faculty of Engineering and Applied Science, Ontario Technical University (UOIT), Oshawa, ON L1G-0C5, Canada 
air over cold water formed the fog (Taylor 1917), which has been widely cited as the cause of marine fog for over a century. As will be noted later, the generality of this conclusion is challenged for Atlantic Canada by a paper in this special edition.

Interest in marine fog was rekindled in the 2000s with many accelerating technological developments in atmospheric measurements. These include the detection of aerosols as nuclei at the resolution of microphysical processes, dynamics of airflow characteristics, atmospheric and oceanographic circulations, radiation, and heat transfer. Surface-based instruments that remotely sense the lower atmosphere, including optical and acoustic probes, remote sensing platforms such as radar and lidar, profiling microwave radiometers, as well as in situ instruments, for observations of fog microphysics found their way into fog research (Gultepe et al. 2007, 2009). Satellite-based measurements with world-wide coverage are widely used to detect the presence of low clouds and fog as well as to investigate cloud microphysical and macro properties including cloud-top temperature, sea-surface temperature, optical thickness, droplet effective size, and liquid water path. Relevant numerical simulations range from coverage of the world at $25-\mathrm{km}$ grid points to the mesoscale and microscale (downs to a few metres). The development of numerical techniques and microscale measurements are used for parametrizations of subgrid-scale physics such as turbulence, radiation, microphysics, and boundary-layer structure. Research grade large-eddy-simulation and direct-numerical-simulation tools have also been developed for cloud and fog investigations (Schwenkel and Maronga 2020).

With greatly improved remote sensing and optical technologies, observational coverage that includes satellites, radars, and microwave radiometers, global numerical model simulations and surface observations are available in near real time. Yet, the predictability of fog remains one of the poorest in meteorology. The Coastal Fog (C-FOG) research program was established with the goal of investigating the aspects of marine coastal fog in one (Canadian Atlantic coast) of the world's two regions of greatest marine-fog occurrence, with the aim of improving our understanding of fog physics as well as identifying and addressing predictability challenges (Fernando et al. 2021). This Boundary-Layer Meteorology special edition consists of C-FOG papers that report significant results from a comprehensive field experiment that took place from 25 August until 8 October 2018. These include measurements made on the Avalon Peninsula, Newfoundland, and at Osborn Head, Nova Scotia, as well as measurements from a dedicated research vessel. The overview of the program is given in Fernando et al. (2021).

There are 14 peer-reviewed papers in this special edition organized into four groups: (1) Synoptic Setting, (2) Microphysics, (3) Atmosphere-Ocean (Turbulent) Boundary Layers, and (4) Modelling and Simulations.

Two papers make up the Synoptic Setting group. Dorman et al. encapsulate the synoptic meteorological conditions during C-FOG. Fog events are examined for the C-FOG main field site at Ferryland, Newfoundland as well as at other Atlantic Canadian airports. A major result, contrary to the widely published view, is that advection fog is not the primary or sole factor for fog occurrence.

The first article by Gultepe et al. summarizes synoptic weather systems affecting the C-FOG campaign area and focuses on remote sensing observations of significant fog events obtained from the GOES-R satellite, profiling microwave radiometers, ceilometers, a micro rain radar, lidar, and their comparisons with ground-based, in situ observations. A major conclusion is that integration of remote sensing and ground-based in situ observations is needed to improve fog prediction.

The second group is on Microphysics. The second article by Gultepe et al. reviews previous fog microphysical research and emphasize suitable microphysical parametrizations 
for numerical-weather-prediction models. They discuss various microphysical parametrizations and present related C-FOG results. They delve into dynamics underlying the coastal-fog life cycle based on visibility parametrizations for fog. Mist and light fog are presented as a function of eddy dissipation rate and fog microphysical parameters.

Qing Wang et al. analyze 15 fog cases observed from the midlatitude west coast of the USA (HELFOG project) as well as observations of the coastal Newfoundland region of the $\mathrm{C}$-FOG project. In addition to revealing the differences in the fog microphysical properties of fog events, the impact of fog on optical propagation representing path-averaged transmission is examined, emphasizing the differences between point and path-averaged values.

Perelet et al. examine fog and rain visibility at the kilometre scale using extinction coefficients from collocated infrared and microwave scintillometers as well as point measurements. They focus on fog properties measured using a two-wavelength scintillometer system and identify the relationships between the amount of liquid water along the radiation path, the size of the droplets, and the path-averaged visibility, with the hope of quantifying the heterogeneity of fog along the path and their relation to point measurements.

Wagh et al. examine two stratus-lowering marine-fog events that include land and ship measurements. Both episodes resulted from the interaction between synoptic-scale nearsurface low-pressure systems and a contiguous high-pressure system. The difference between microphysical variables and droplet distribution in these two events, as well as within the same fog layer, are studied.

Chisholm et al. characterize the size distribution and chemical composition of ambient aerosols during fog-free times in the C-FOG study. The aerosol size distribution during periods of processed marine air are usually bimodal, while those in St. John's and Halifax harbour show signs of local emissions. Two cases of particle growth observations conceivably influenced by the free troposphere, as well as continental and marine sources, are analyzed and microphysical processes that influence the impact of marine aerosols on fog occurrence are highlighted.

The third group contains Atmospheric and Ocean Boundary Layer studies, especially related to turbulence. Sen Wang et al. present a detailed account of a coastal-fog event encountered during C-FOG campaign from the research vessel, and discuss the multi-layered fog-cloud structure and counter-gradient sensible heat fluxes during the event.

Grachev et al. analyze turbulence and mean meteorological variables to examine airsea/land coupling in the coastal zone with and without fog, based on the data collected at four levels of a 16.2-m flux tower located at the Downs measurement site in Ferryland. The focus is primarily on the applicability of Monin-Obukhov similarity theory for foggy conditions, thus providing modellers with a database on turbulence in coastal fog-laden air.

Lozovatsky et al. focus on ocean turbulence and mixing near the shelf break south-east of Nova Scotia. A strong vertical gradient of mixing was found between the westward-directed oceanic surface currents and the eastward flow in the pycnocline below the sharp density jump at the shelf break and on the continental slope. This, in combination with weak stratification in the pycnocline, led to frequent development of shear-induced turbulence events.

The fourth group concerns Modelling and Simulations. Dimitrova et al. simulate coastal fog in the Canadian Atlantic using the Weather Research and Forecasting model. A sensitivity study points to multiple strategies related to microphysical and boundary-layer parameterizations that may improve the forecast of coastal fog and capture air-sea interactions. They note that existing microphysical schemes do not represent nuances of atmospheric-boundary-layer physics affecting coastal-fog formation.

Wainwright et al. investigate the sensitivity of marine fog to physical and microphysical processes using large-eddy simulation in relation to the formation and maintenance of marine 
fog. Factors considered include the cloud-droplet number concentration, turbulent mixing, and air-sea temperature difference. The strength of the fog (in terms of liquid water content) appears to be highly sensitive to all three factors. Varying only the cloud-droplet number concentration, within a range of physically realistic values for marine regions, can lead to a difference between fog halving or doubling in liquid water content.

Bardoel et al. present a case where a cold-frontal airmass collides with the Ferryland peninsula to produce mixing fog. The collision causes turbulent mixing of nearly saturated ambient air with an almost saturated cold-frontal airmass, creating conditions for mixing fog. The underlying dynamics are elucidated using laboratory experiments, where a collision of a lockexchange-induced gravity current with a rectangular obstacle mimicks the natural case. Laboratory results show good agreement with field conditions.

Finally, Richter et al. use an advanced Lagrangian cloud model coupled to large-eddy simulation to capture the onset of fog formation, focusing on microphysical details of aerosol activation and the vital role of aerosol hygroscopicity. Accordingly, fog could easily contain a mix of activated pollution aerosols and fog droplets. Their results suggest that fog cannot be easily represented in numerical-weather-prediction models by using bulk microphysical schemes.

Acknowledgements The research appearing this special issue was funded by ONR Grant N00014-18-1-2472 (Marine Meteorology and Space Program) as a Multidisciplinary Initiative. We thank the initiative, commitment, and guidance of ONR Program Officer Daniel Eleuterio and Assistant Program Officers Katherine Mulreany and Joshua Cossuth.

\section{References}

Dorman CE, Mejia J, Koračin D, McEvoy D (2017) Worldwide marine fog occurrence and climatology. In: Koračin D, Dorman CE (eds) Marine fog: challenges and advancements in observations, modeling, and forecasting. Springer International Publishing, Switzerland, pp 7-152. https://doi.org/10.1007/ 978-3-319-45229-6_2

Fernando HJS, Gultepe I, Dorman C, Pardyjak E, Wang Q, Hoch SW, Richter D, Creegan E, Gaberšek S, Bullock T, Hocut C, Chang R, Alappattu D, Dimitrova R, Flagg D, Grachev A, Krishnamurthy R, Singh DK, Lozovatsky I, Nagare B, Sharma A, Wagh S, Wainwright C, Wroblewski M, Yamaguchi R, Bardoel S, Coppersmith RS, Chisholm N, Gonzalez E, Gunawardena N, Hyde O, Morrison T, Olson A, Perelet A, Perrie W, Wang S, Wauer B (2021) C-FOG: life of coastal fog. Bull Am Meteorol Soc 102:E244-E272. https://doi.org/10.1175/BAMS-D-19-0070.1

Gultepe I, Tardif R, Michaelides SC, Cermak J, Bott A, Bendix J, Müller M, Pagowski M, Hansen B, Ellrod G, Jacobs W, Toth G, Cober SG (2007) Fog research: a review of past achievements and future perspectives. Pure Appl Geophys 164:1121-1159. https://doi.org/10.1007/s00024-007-0211-x

Gultepe I, Pearson G, Milbrandt JA, Hansen B, Platnick S, Taylor P, Gordon M, Oakley JP, Cober SG (2009) The fog remote sensing and modeling field project. Bull Am Meteorol Soc 90:341-359. https://doi.org/10. 1175/2008BAMS2354.1

Lawrence EN (2000) The titanic disaster: a meteorologist's perspective. Weather 55:66-78. https://doi.org/10. 1002/j.1477-8696.2000.tb04034.x

Schwenkel J, Maronga B (2020) Towards a better representation of fog microphysics in large-eddy simulations based on an embedded Lagrangian cloud model. Atmos 11:466. https://doi.org/10.3390/atmos11050466

Taylor GI (1915) Eddy motion in the atmosphere. Philos Trans R Soc Ser A 215:523-537. https://doi.org/10. 1098/rsta.1915.0001

Taylor GI (1917) The formation of fog and mist. Q J R Meteorol Soc 43:241-268. https://doi.org/10.1002/qj. 49704318302

Publisher's Note Springer Nature remains neutral with regard to jurisdictional claims in published maps and institutional affiliations. 